\title{
Assessing Students' Creative Disposition and Creative Product in Learning Newton Law
}

\author{
Melli Indah Suciani ${ }^{1}$, Eka Cahya Prima ${ }^{2}$ \\ \{melliindah2402@gmail.com ${ }^{1}$, ekacahyaprima@upi.edu² $\}$ \\ Department of Science Education, Faculty of Mathematics and Science Education, Universitas \\ Pendidikan Indonesia, Bandung, Indonesia ${ }^{1,2}$
}

\begin{abstract}
Creativity is one of the outputs that should be existed in students. The purpose of this research is to investigate the effect of the lesson on students' creative disposition and creativity in learning Newtons' Law and its relations. In this research sample was taken by purposive sampling participated by 77 students of 8 th-grade students at Junior High School in Garut. The data was obtained by making a creative product and constructed a questionnaire. It is the result of the creative dispositions questionnaire which has a total average of $75.58 \%$. The result of a creative product scored using Creative Measurement Tools has a total average of about $73 \%$. Students' creative disposition in learning newton law can build students' creativity in making the creative product and proved by the result of correlation analysis which is 0.593 that significant at the 0.05 level.
\end{abstract}

Keywords: Creative Disposition, Students' Creativity, Newtons Law, Descriptive Research

\section{Introduction}

Learning science is very important to affect society and the environment, but learning science is relatively difficult, for both successful and unsuccessful students [1]. In a traditional science class, a teacher stands at the front of the class and teaching a passive group of students. Those students then go and do the homework problems from the textbook and take exams that are similar to those exercises [2]. The main actor in the class is the teacher, and it is not appropriate with the condition that should be build which is the teacher is the facilitator inside the class and students should be the main. This kind of situation is not too right to learn science because in line with the statement of UNESCO that science is relatively tricky. Thus, the teacher should create a good condition to increase student's willing and engaging in learning science that will make the students more comfortable to understand science itself.

One of the ways to make students interested in learning science is making creative lessons. Creative lessons should encourage students to "think outside the box and come up with so many ideas. The creativity of students and teachers are a significant role in the learning and teaching process. Students must feel that they are expected to be a creative person. According to Trnova and Trev [3], the effective teaching strategies influencing creativity are student-centered activities, the link between teaching contents and real-life, management of skills in class, open-ended questions, encouragement of creative thinking and use of technology and multimedia. 
Creativity is one of the outputs that should be existed in students. Especially in science, the student is treated to be creative to implement their knowledge in their daily life. There are many different views about what creativity is and how it should be assessed. And in many national curricula creativity is only implicitly acknowledged and seldom precisely defined [4]. Research on creativity often has three directions of impact: the creative product, the creative process, and the creative person [5]. In this research, students should make a product to show creativity as a creative process of a creative person. As science educators and science teachers can do is to provide an environment that increases the possibilities for creativity to emerge Creativity can be defined qualitatively and quantitatively: creative persons can create a lot of new (quantitative aspect) and useful (qualitative aspect) products [5]. Most simply, different people have different ways of interpreting creativity. Because of that kind of subjectivity, the creativity in this research will be measured by Creativity Measurement Tool (CMET).

Besides creativity, the creative disposition of students will be measured. A disposition is a pattern of behavior exhibited frequently and in the absence of coercion and constituting a habit of mind under some conscious and voluntary control, and that is intentional and oriented to broad goals [6]. Dispositions are frequent and voluntary habits of thinking and doing [7]. Teachers can diligently plan learning experiences that help children acquire skills and the disposition to use those skills. The creative disposition itself will be measured according to Lucas, Claxton, and Spencer [4] which are inquisitive, persistent, collaborative, imaginative, and disciplined.

Meanwhile, the researcher expects that each student will produce different creativity based on their prior knowledge, lesson, and their experience. By making a product and state their creative thinking along the creative process, students are expected to be mastering or understanding the content regarding Newton Law in physics subject. Newton Law is chosen in this research because in this topic many things can be implemented in student's daily life. Besides, the previous research state that the student teachers' have significant weaknesses in understanding the terms of fundamental knowledge of Newton's Laws of Motion. This may stem from the lack of student teachers to relate scientific knowledge with real-life phenomena and experiences [8].

Meanwhile, according to Prima, Putri, and Rastaman [9], Physics study should begin early in a student's academic life, which will promote their interest and potential for pursuing more rigorous physics courses later on. Instruction in the upper elementary years can introduce physics principles and provide the foundation for more in-depth physics learning. So, the researcher expects the students can create simple products regarding the topic to treat the student to relate scientific knowledge with real life and to promote student's interest and potential in learning physics. In the last, students should fill the questionnaire prepared by the researcher. The questionnaire will be based on five dispositions according to Lucas, Claxton, and Spencer [4]. The score of the questionnaire and the score of creative products will be used to investigate the relationship between their creative dispositions and the creative product that they made.

\section{Research Method}

The method used for this research is descriptive. This research is focused on students' creative disposition in learning Newton Law without considering student's achievement. Besides that, the objects of research are not given any treatment. The design of the study that 
used is the qualitative description. The researcher assigns two groups and conducts observations during teaching and lesson regarding creative disposition and students' creativity. The location of this research is X school in Garut. The population of this research will be 8thgrade students at $\mathrm{X}$ school. The samples are two classes of 8th-grade students. The sampling technique will be purposive sampling.

\section{Result and Discussion}

\subsection{Creative Disposition}

Students' creative disposition that was measured in this research involves five creative disposition models which are inquisitive, persistent, imaginative, collaborative and disciplined that stated by Lucas, Claxton, and Spencer [4]. The researcher used 45 statements in a questionnaire to analyze and measure students' creative disposition. The questionnaire responded by choosing five scales which are very often, often, sometimes, rarely and never. The result of the student's creative disposition dimension as in Figure 1.

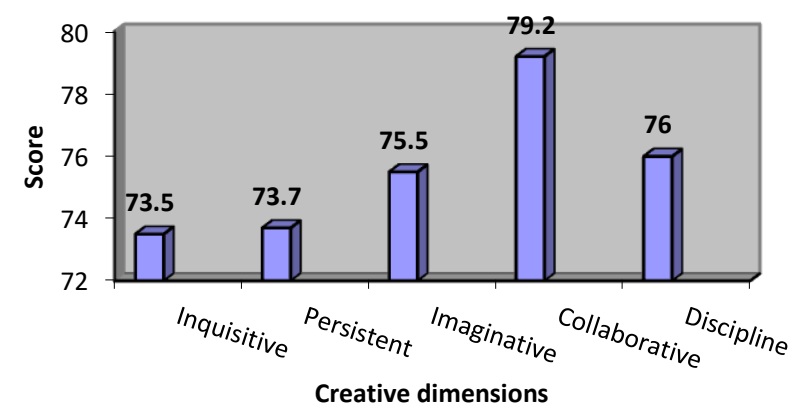

Fig. 1. The recapitulation of the creative disposition dimensions.

The result in Figure 1 shows the recapitulation of the creative disposition dimension of students in each dimension. Based on the figure, each dimension has no significant differences in the result because all of the dimensions' results are above $70 \%$ and under $80 \%$. For inquisitive, the students reach $73.5 \%$, persistent $73.7 \%$, Imaginative $75.5 \%$, collaborative $79.2 \%$, and discipline $76.0 \%$. All of the dimensions categorized as enough based on Zainal (2014).

The highest result is in a collaborative dimension; it means that the habit of students is excellent in sharing the product, giving and receiving feedback and cooperate appropriately [4], while the lowest result is inquisitive. It does not mean that students are bad in inquisitive dimensions, because the result is $73.5 \%$ and it also categorized as enough. Sub-elements that include inquisitive are wondering/questioning, exploring/investigating, and challenging/ assumptions.

According to Katz [6] disposition is a pattern of behavior exhibited frequently and in the absence of coercion and constituting a habit of mind under some conscious and voluntary control, and that is intentional and oriented to broad goals. Because disposition is a pattern of behavior exhibited frequently, the questionnaire was given at the end of the teaching and 
lesson to check student's impressions during activities. The result of a questionnaire filled by 70 students shows that the highest score was collaborative, which is sharing the product, giving and receiving feedback, and cooperating appropriately. This result is in line with Voseles and Haughey [7] that teachers can diligently plan learning experiences that help children acquire skills and the disposition to use those skills. Because in this research teacher plan experiment as learning experiences which is make a creative product to help students improve skills in term of creativity, so that the highest is in collaborative dimensions. Students asked to make a creative product-based on Newton law as a final project without any limitation. Students can express creativity freely.

Before doing a final project, students learn about Newton law in some meetings. During that learning and teaching activities before the final project, students guided to ask some questions to the teacher or friends. The teacher always gives time for questions and answer sessions to make sure that students understand the lesson. But based on the result, wondering and questioning, exploring and investigating, and challenging assumptions which are included inquisitive dimensions got the lowest score. It might the confidence of students is low, or the students are nervous because of the existence of the researcher inside the classroom.

\subsection{Students' creativity Product}

In this research, students made creative products. The teacher did not give any limitation in order to show students' creativity. Students are able to use any type of equipment or materials that needed to make the product as long as the equipment and materials are safe and allowed by the rule of the school. Student's creative products were measured using creative measurement tools $(\mathrm{CMeT})$. A quantitative measurement tool is possible to help users to evaluate the creativity product. The student's creative product results are shown in Figure 2.

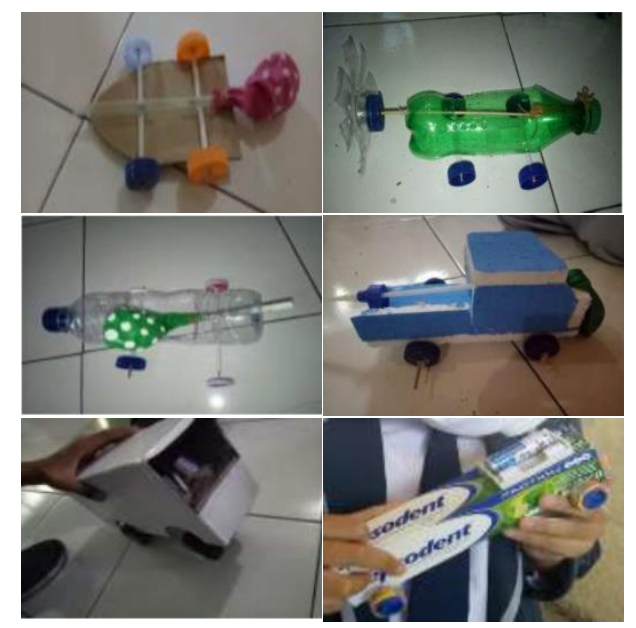

Fig. 2. Students' creative products.

The result in Table 1 . shows the highest percentage is usability $82 \%$ that categorized as good. Meanwhile, novelty is $75 \%$, effectiveness $73 \%$ and categorized as good, aesthetic value is $64 \%$ which is 'categorized as enough. The result and analysis will be presented to get more 
understanding of students' creativity as follows that have been classified as three levels for the representation.

The cost spent to make the product by the result. The used of chosen materials to create this creative product make the maintenance of this product is easy to conducted and does not need special treatment. Besides that, the process and materials used are safe. The creative product made by group twelve is inspiring because it is very easy to make except the use of battery and becomes a very good habit when students try to make something more useful. Students used the battery from their old toy car.

The diversity of creative products made by students shows that every group has different creativity. Before making the creative product, every group is given time to discuss and sketch the simple car toy that will be made. In the discussion session, every student should provide the opinion and then it combined as a group plan. Students made the creative product together in a group.

Table 1. The result of students' creativity products.

\begin{tabular}{|c|c|c|c|c|c|c|}
\hline No & $\begin{array}{l}\text { Creative } \\
\text { Dimension }\end{array}$ & Element & $\begin{array}{l}\text { Total Average } \\
\text { (14 Groups) }\end{array}$ & $\begin{array}{l}\text { Total } \\
(\%)\end{array}$ & Average & Description \\
\hline \multirow[t]{7}{*}{1} & \multirow{7}{*}{ Novelty } & Original & 3.86 & $77 \%$ & & \\
\hline & & New & 3.86 & $77 \%$ & & \\
\hline & & Obvious & 4.21 & $84 \%$ & & \\
\hline & & Valuable & 4.07 & $81 \%$ & & \\
\hline & & Unexpected & 3.14 & $63 \%$ & & \\
\hline & & Challenging & 3.21 & $64 \%$ & & \\
\hline & & Average & 3.73 & $75 \%$ & & good \\
\hline \multirow[t]{7}{*}{2} & \multirow[t]{7}{*}{ Usability } & Learnable & 4.07 & $81 \%$ & & \\
\hline & & Operable & 3.79 & $76 \%$ & & \\
\hline & & Practical & 4.71 & $94 \%$ & & \\
\hline & & Size & 3.64 & $73 \%$ & & \\
\hline & & Dynamic & 4.36 & $87 \%$ & & \\
\hline & & $\begin{array}{l}\text { Material } \\
\text { durability }\end{array}$ & 3.93 & $79 \%$ & & \\
\hline & & Average & 4.08 & $82 \%$ & & good \\
\hline \multirow[t]{5}{*}{3} & \multirow[t]{5}{*}{ Effectiveness } & Cost & 4.21 & $84 \%$ & & \\
\hline & & Maintenance & 4.00 & $80 \%$ & & \\
\hline & & Safety & 3.86 & $77 \%$ & & \\
\hline & & Marketability & 2.50 & $50 \%$ & & \\
\hline & & Average & 3.64 & $73 \%$ & & good \\
\hline \multirow[t]{8}{*}{4} & \multirow[t]{8}{*}{ Aesthetic Value } & Trendsetting & 2.50 & $50 \%$ & & \\
\hline & & Organized & 4.50 & $90 \%$ & & \\
\hline & & $\begin{array}{l}\text { Commercializatio } \\
\mathrm{n}\end{array}$ & 1.57 & $31 \%$ & & \\
\hline & & Inspiring & 3.14 & $63 \%$ & & \\
\hline & & Green & 3.64 & $73 \%$ & & \\
\hline & & Elegant & 3.57 & $71 \%$ & & \\
\hline & & Risk-Taking & 3.57 & $71 \%$ & & \\
\hline & & Average & 3.21 & $64 \%$ & & enough \\
\hline \multicolumn{2}{|c|}{ Total Score } & & 3.65 & $73 \%$ & & \\
\hline
\end{tabular}

Students' Science Literacy Analysis. After the researcher got the recapitulation of the creative disposition score based on the questionnaire and creative product score based on 
products that created, the researcher wants to analyze the relationship between both of the scores. Is the students' creative disposition in learning Newton Law will influence the student's creative product or not? So, this calculation of correlation between both of the scores is needed. Before calculating the relationship, the total average score and percentage of each group will be recapitulated. Table 2 is used to show the score of students' creative dispositions and creative products:

Table 2. The recapitulation of creative disposition and creative products.

\begin{tabular}{lllll}
\hline Group & \multicolumn{2}{l}{ Creative Disposition } & \multicolumn{2}{l}{ Creative Product } \\
& Average & Percentage (\%) & Average & Percentage (\%) \\
\hline 1 & 3.60 & 72.09 & 2.74 & 55 \\
2 & 3.61 & 72.27 & 3.30 & 66 \\
3 & 3.92 & 78.31 & 3.91 & 78 \\
4 & 3.67 & 73.44 & 3.43 & 69 \\
5 & 3.74 & 74.78 & 3.96 & 79 \\
6 & 3.91 & 78.22 & 4.35 & 87 \\
7 & 3.80 & 76.00 & 3.57 & 71 \\
8 & 3.76 & 75.19 & 3.61 & 72 \\
9 & 3.75 & 75.04 & 3.70 & 74 \\
10 & 3.94 & 78.81 & 3.35 & 67 \\
11 & 3.84 & 76.81 & 3.87 & 77 \\
12 & 3.77 & 75.38 & 3.65 & 73 \\
13 & 3.84 & 76.80 & 4.48 & 90 \\
14 & 3.64 & 72.89 & 3.26 & 65 \\
\hline
\end{tabular}

Six groups have a higher score of creative products than a score of creative dispositions score. In other words, a group that has a good score of creative dispositions are able to create a higher score of creative products. Besides that, two of the group have a similar score of creative dispositions and creative products. While six of groups have a lower score of creative products than creative dispositions. It means that not every higher score of creative dispositions will increase the score of creative products. To make more understand, the result is shown in Figure 3.

Not all of the higher scores of creative dispositions will create a higher score of creative products. For example, the tenth group who has the highest score of creative disposition which is 3.94 , has a creative product score of about 3.61. While, the highest score of creative dispositions were reached by three groups which are 4.07 and have a different score of creative product which is $3.74,3.84$, and 3.91. Therefore to make clearer about the result, the researcher needs a tool that can show the correlation between creative disposition and creative product result.

To analyze the correlation between creative disposition and creative product results, researchers use Spearman's rho. Multiple regression or correlation analysis (MRC) is a highly general and very flexible data analytic system and may be used whenever a quantitative variable the dependent variable (Y) is to be studied as a function of any factors of interest the independent variables (IVs). And the result of the correlation between creative disposition and creative product analysis is shown in Table 3 . 


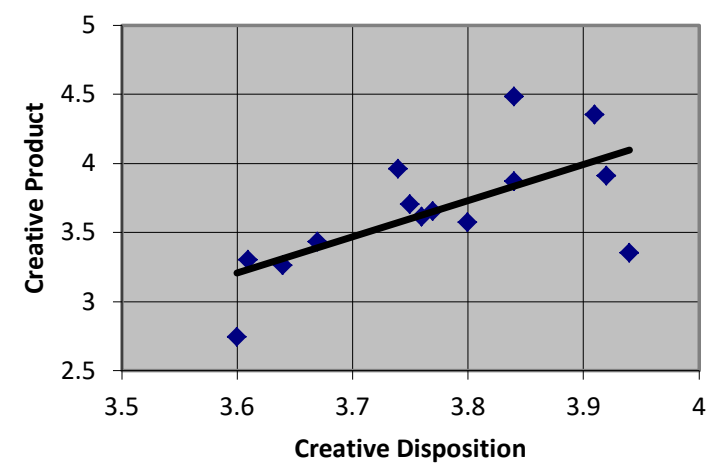

Fig. 3. The correlation between creative dispositions and creative products.

Table 3. The result of correlations between creative disposition and creative products using spearman's rho.

\begin{tabular}{|c|c|c|c|c|}
\hline Analysis & Aspect & Details & Creative disposition & Creative product \\
\hline \multirow{8}{*}{$\begin{array}{l}\text { Spearman's } \\
\text { rho }\end{array}$} & Creative & Correlation & 1.000 & $.593^{*}$ \\
\hline & disposition & Coefficient & & \\
\hline & & Sig. (2-tailed) & . & .026 \\
\hline & & $\mathrm{N}$ & 14 & 14 \\
\hline & Creative & Correlation & $.593^{*}$ & 1.000 \\
\hline & product & Coefficient & & \\
\hline & & Sig. (2-tailed) & .026 & . \\
\hline & & $\mathrm{N}$ & 14 & 14 \\
\hline *. Correlatic & s significan & $\mathrm{t}$ the 0.05 level & (led). & \\
\hline
\end{tabular}

According to Moore, Notz, and Flinger [10] that the correlation $(r)$ measures the strength of the linear relationship between two quantitative variables. The output showed that the correlation between creative disposition and the creative product is 0.633 which shown the strength of correlation between creative disposition and creative product. The result of the correlation test using SPSS shows that it is significant at the 0.05 level which means there is a correlation between the result of creative disposition and creative product made by students. The higher score of creative disposition in line with a higher creative product that students got. The result is in line with the previous research by Hanke, Ifenthaler, and Seel [5] regarding the effect disposition on the design of a lesson that more creative participants design more varied lessons.

\section{Conclusion}

Students' creative disposition in learning newton law can improve students' creativity in making the creative product. It can be proved by the result of correlation analysis using SPSS, which is 0.633 that significant at the 0.05 level. The higher score of creative disposition in line with a higher creative product that students got. The result of this research is in line with previous research by Hanke, Ifenthaler, and Seel [5] regarding the effect of creative 
disposition on the design of lessons which stated that more creative participants design more varied lessons.

\section{References}

[1] United Nations Educational, Scientific and Cultural Organization.: Educational Research: Some Basic Concepts and Terminology (2005)

[2] Wieman, C.: Why not try a scientific approach to science education? Change: The Magazine of Higher Learning, 39(5), pp. 9-15 (2007)

[3] Trnova, E. and Trna, J.: Implementation of creativity in science teacher training. International Journal on New Trends in Education and Their Implications, 5(3), pp. 54-63 (2014)

[4] Lucas, B., Claxton, G. and Spencer, E.: Progression in student creativity in school: first steps towards new forms of formative assessments. Contemporary Readings in Law \& Social Justice, 6(2) (2014)

[5] Hanke, U., Ifenthaler, D. and M Seel, N.: Effects of creative dispositions on the design of lessons. The Open Education Journal, 4(1) (2011)

[6] Katz, L.G.: Dispositions: Definitions and Implications for Early Childhood Practices. Perspectives from ERIC/EECE: A Monograph Series, No. 4 (1993)

[7] Da Ros-Voseles, D. and Fowler-Haughey, S.: Why children's dispositions should matter to all teachers. Beyond the Journal: Young Children on the Web, 1(3), 1-7 (2007)

[8] Arslan, A.S. and Y. Devecioglu.: Students Teachers' Level of Understanding and Model of Understanding about Newton's Law of Motion. Asia-Pacific Forum on Science Learning and Teaching, 11(1), pp. 1-20 (2010)

[9] Prima, E.C., Utari, S., Chandra, D.T., Hasanah, L. and Rusdiana, D.: Heat and temperature experiment designs to support students' conception on nature of science. JOTSE: Journal of technology and science education, 8(4), pp. 453-472 (2018)

[10] Moore, D.S., Notz, W.I and Flinger, M.A.: The Basic Practice of Statistics (6th Ed.). New York:

W. H. Freeman and Company (2013) 